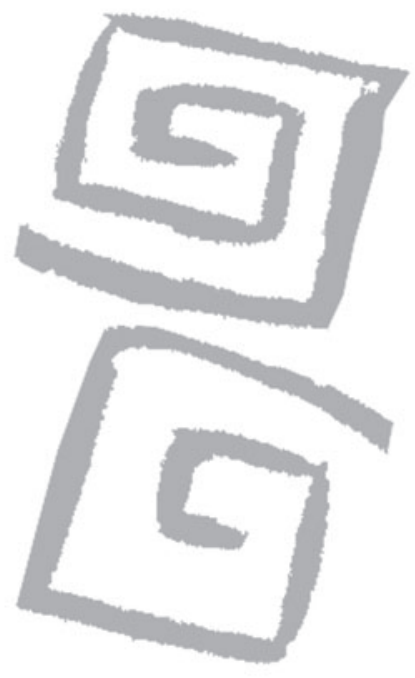

\title{
El tratamiento del dolor por cáncer en el final de la vida: estudio de caso en un servicio de cuidados paliativos de la Ciudad Autónoma de Buenos Aires
}

\author{
Treatment for cancer pain at the end of life: a case \\ study in a palliative care service in the Autonomous \\ City of Buenos Aires
}

Alonso, Juan Pedro ${ }^{1}$

'Doctor en Ciencias Sociales. Becario posdoctoral, Consejo Nacional de Investigaciones Científicas y Técnicas (CONICET), Instituto de Investigaciones Gino Germani, Universidad de Buenos Aires, Argentina. juan_alonso79@hotmail.com
RESUMEN La prevención y el alivio del dolor por cáncer, definidos en las últimas décadas como un desafío para la salud pública a nivel internacional, han sido planteados recientemente en los debates públicos como una cuestión de derechos humanos. Pese a ello, existen importantes barreras para la provisión de tratamientos adecuados. El artículo analiza el tratamiento del dolor por cáncer en un servicio de cuidados paliativos de la Ciudad Autónoma de Buenos Aires, poniendo el foco en la forma en que profesionales y pacientes instrumentan y negocian los términos y la adherencia al tratamiento del dolor. A partir de un abordaje cualitativo, que triangula datos de entrevistas semiestructuradas y observaciones etnográficas, el artículo describe la forma en que el dolor es objetivado y medido, y las estrategias de los profesionales para consensuar los protocolos de tratamiento. Asimismo, se describe el modo en que los profesionales construyen en la práctica una retórica del derecho al alivio del dolor y se discuten sus límites.

PALABRAS CLAVES Dolor; Neoplasias; Cuidados Paliativos al Final de la Vida; Derechos del Paciente; Argentina.

\begin{abstract}
Cancer pain relief has been defined as a worldwide public health challenge in the last decades and has recently been included in public debates as a human rights issue. However, barriers to the provision of adequate pain management continue to exist. This article analyzes the cancer pain treatment provided in a palliative care setting in the Autonomous City of Buenos Aires, focusing on how professionals and patients implement and negotiate the terms and adherence to the pain treatment. Based on a qualitative approach that triangulates data from semi-structured interviews and from ethnographic observations, the article addresses the way pain is measured and assessed and the strategies of health professionals in establishing pain treatment protocols. The article also describes the rhetoric regarding the right to pain relief developed by health professionals through their practice and discusses the limitations of that rhetoric.
\end{abstract}

KEY WORDS Pain; Neoplasms; Hospice Care; Patient Rights; Argentina. 


\section{INTRODUCCIÓN}

La consigna de "luchar contra el dolor" es un imperativo relativamente nuevo en la medicina occidental: recién a finales del siglo XX la lucha contra el dolor es definida como una prioridad para la salud pública (1). En la década de 1980, la Organización Mundial de la Salud (OMS) promueve la prevención y el alivio del dolor por cáncer como uno de los mayores desafíos de la salud pública, e invoca a los servicios de salud a garantizar el derecho de los pacientes oncológicos a ser librados de dolores evitables (2). Más recientemente, y de la mano del desarrollo de los cuidados paliativos, el alivio del dolor comienza a pronunciarse como una cuestión de derechos humanos $(3,4)$. Como señalan Brennan et al. (5 p.206), en los últimos años, desarrollos en el campo de la medicina, la ética y el derecho han generado un consenso internacional en torno a considerar las fallas en el tratamiento del dolor como "una medicina pobre, una práctica poco ética, y la abrogación de un derecho humano fundamental".

A pesar de estos desarrollos y avances $-y$ de las dificultades metodológicas para estimar su prevalencia- estudios previos y revisiones de la literatura señalan que buena parte de los pacientes oncológicos no tiene acceso a tratamientos para el alivio del dolor, que continúa siendo un problema de salud pública a nivel internacional (3-7). Entre las causas de este desfasaje se señalan cuestiones ligadas a las políticas sanitarias que fallan en garantizar la disponibilidad, accesibilidad y asequibilidad de los opioides; la inadecuada formación de los profesionales de la salud; y las representaciones compartidas por pacientes y profesionales que obstaculizan un tratamiento efectivo, como la inevitabilidad del dolor, el temor a la adicción y la dependencia a los opioides, entre otros $(5,6)$. En Argentina no hay estudios epidemiológicos sobre la prevalencia del dolor por cáncer pero, a partir de indicadores como el consumo promedio de medicamentos opioides utilizado por la OMS como criterio para medir los progresos en el tratamiento del dolor por cáncer, se estima que buena parte de los pacientes oncológicos no accede a tratamientos adecuados (8) (a).

El objetivo de este artículo es analizar el tratamiento del dolor por cáncer en el final de la vida, poniendo el foco en cómo profesionales y pacientes de cuidados paliativos instrumentan y negocian los términos y la adherencia al tratamiento del dolor en la práctica. El trabajo se enmarca en una investigación más amplia sobre la forma en que el final de la vida es gestionado en servicios de cuidados paliativos, disciplina médica especializada en la atención de pacientes terminales. Definida como un abordaje que apunta a mejorar la calidad de vida de pacientes y familiares a través de la prevención y el alivio del sufrimiento desde un abordaje multidisciplinario (9), la disciplina sustenta su expertise en el tratamiento sintomático, especialmente en la evaluación y el tratamiento del dolor por cáncer (10).

A partir de un estudio de caso y de un abordaje metodológico cualitativo, el artículo analiza las estrategias de los profesionales de cuidados paliativos para consensuar los términos del tratamiento del dolor en las consultas clínicas. Esto supone un trabajo pedagógico sobre la aplicación de escalas y de los beneficios del tratamiento preventivo, comprometer a los pacientes en el tratamiento y trabajar sobre las imágenes negativas que muchos pacientes tienen de los medicamentos opioides, que se inscribe en la retórica de considerar el alivio del dolor en tanto derecho.

\section{El tratamiento del dolor por cáncer}

Los primeros estudios que desde las ciencias sociales abordaron la temática exploraron la incidencia de la cultura y la socialización en las manifestaciones y actitudes en relación al dolor (11). En las últimas décadas, la sociología de la salud y la antropología médica abordaron extensamente la problemática del dolor crónico. Las investigaciones exploran la forma en que el dolor crónico es gestionado en determinados dispositivos médicos, como las clínicas para atender a este tipo de patologías (1,12-15); así como la experiencia subjetiva de vivir con dolor crónico y la forma en que esta experiencia interpela al cuerpo y la subjetividad (16-19). Por su parte, desde una perspectiva sociohistórica se ha analizado la construcción del tratamiento del dolor como una especialidad médica (1), y las conceptualizaciones e innovaciones en la terapéutica del dolor por cáncer en el campo de los cuidados paliativos $(10,20,21)$. 
Diversos autores han señalado críticamente la forma en que la biomedicina concibe el dolor, definido como una sensación que puede ser medida objetivamente, clasificada y tratada mediante parámetros universales $(16,22,23)$. En los últimos años, sin embargo, se modificó el paradigma dominante de la conceptualización del dolor en el mundo médico, incorporando la centralidad de los componentes sociales, culturales y psicológicos $(1,20,21)$.

A partir de la segunda mitad del siglo $X X$, el tratamiento del dolor sufrió importantes innovaciones conceptuales y técnicas (20). En primer lugar, debido a la emergencia de una medicina del dolor, en torno a la figura del anestesista norteamericano John J. Bonica. Esta nueva medicina, que define para sí el dolor como objeto -y ya no como mero síntoma-, se apoya en un enfoque holista de la persona y propone un abordaje multidisciplinario para la investigación y el tratamiento del dolor (1). Por su parte, el trabajo de Cicely Saunders -figura central en la emergencia de los cuidados paliativos- contribuye a la configuración de una medicina del dolor que aporta una conceptualización que integra los aspectos psicológicos, sociales, emocionales y espirituales del dolor e investigaciones en el uso de medicamentos opioides para el control del dolor en el final de la vida (21). Asimismo, en las últimas décadas se desarrollaron nuevas formas de medir y evaluar el dolor de los pacientes y los efectos analgésicos de las terapias (24), y se crearon protocolos de tratamiento del dolor para enfermedades oncológicas (25).

Estos aportes son recuperados en las normativas de la OMS respecto al tratamiento del dolor por cáncer, delineadas en torno a estos elementos:

a) el control de este tipo de dolores requiere de un tratamiento preventivo (los analgésicos se prescriben a intervalos regulares y no según la necesidad momentánea del paciente);

b) la evaluación de la intensidad del dolor y la efectividad del tratamiento a partir de escalas numéricas;

c) la adecuación de los analgésicos a la intensidad del dolor, ajustando la fuerza de la medicación de acuerdo a la intensidad del dolor $(9,25)$.
En este artículo se analiza cómo este protocolo funciona en la práctica: es decir, la forma en que los profesionales y los pacientes de cuidados paliativos negocian y definen el significado, la adherencia y los éxitos y fracasos del tratamiento en sus interacciones cotidianas en el hospital, construyendo en la práctica una retórica en torno al derecho al alivio del dolor.

\section{METODOLOGÍA}

Los datos analizados en este artículo forman parte de una investigación realizada con profesionales y pacientes de un servicio de cuidados paliativos en un hospital público de la Ciudad Autónoma de Buenos Aires entre los años 2006 y 2009 (b). El diseño metodológico siguió una estrategia cualitativa (26), basada en la combinación de técnicas de recolección de datos, como observaciones etnográficas en el servicio, entrevistas semiestructuradas y charlas informales con profesionales y pacientes.

El trabajo de campo etnográfico (27) consistió en la participación en diferentes espacios y situaciones en el servicio, como reuniones de equipo, pases de sala y consultas médicas con pacientes y familiares por un período de 13 meses. Se realizaron entrevistas semiestructuradas con profesionales y pacientes (c). Se entrevistaron a 24 integrantes del servicio de cuidados paliativos (7 profesionales médicos, 2 de psicología, 9 de enfermería, una trabajadora social, una terapista ocupacional y 4 voluntarios legos). Respecto a los pacientes, se conformó una muestra intencional controlada por cuotas de sexo y edad: se entrevistaron a 30 pacientes, 16 mujeres y 14 varones, con una edad promedio de 58 años. Los pacientes fueron contactados en el servicio, donde se pactó un encuentro para realizar las entrevistas. Las mismas se llevaron a cabo en el bar del hospital, en las habitaciones privadas de los pacientes o en la sala de reuniones del servicio, y otras fueron realizadas en el domicilio de los pacientes. En todos los casos se procuró realizar las entrevistas en un espacio que permitiera respetar la privacidad de los entrevistados y que no estuvieran presentes profesionales del servicio. 
Las entrevistas y observaciones se realizaron con el consentimiento de pacientes y profesionales, informados del carácter y los objetivos de la investigación, que contó con la autorización de las autoridades del servicio y con la aprobación de los Comités de Ética y de Docencia e Investigación del hospital. Se han omitido o modificado detalles en las citas textuales de las entrevistas y en las observaciones reseñadas para proteger el anonimato de los participantes. El material etnográfico fue registrado en un cuaderno de campo y junto con el texto desgrabado de las entrevistas codificado en un programa para el análisis de datos cualitativos (ATLAS.ti), a partir de un análisis inductivo (28).

En la decisión de realizar la investigación en un único servicio se resolvió privilegiar una inserción prolongada en un mismo espacio, elección que conlleva limitaciones lógicas a la posibilidad de extrapolar los resultados. En la elección del servicio -pionero de la disciplina y referente en el país y en América Latina (d) - se atendió tanto a cuestiones relativas a la factibilidad (no menores en proyectos de este tipo) como a la relevancia del caso (29).

\section{RESULTADOS}

\section{El tratamiento del dolor en cuidados paliativos}

El control del dolor es uno de los principales motivos de la llegada de los pacientes al servicio de cuidados paliativos. Salvo en los casos en que son derivados de manera explícita para un tratamiento más eficaz del dolor, los pacientes refieren experiencias de desatención o deslegitimación de sus padecimientos en su trayectoria previa en los servicios de salud (30). Analizando sus trayectorias, se hace evidente la dificultad que los pacientes experimentan para encontrar respuesta a sus sensaciones de dolor:

Entrevistador: ¿Usted no hacía tratamiento para el dolor?

Paciente: No, el otro doctor directamente no me daba nada. Decía que no me podía dar otra cosa porque era muy fuerte. No me daba nada. Entrevistador: ¿Y usted alguna vez pidió la medicación para el dolor?
Paciente: Claro, algo para los dolores, sí le pedí, pero me dio solamente Ibuprofeno, cosa que los primeros días me hacía efecto, pero después ya no. Porque eran demasiados los dolores y no, no me hacía nada. (Entrevista a paciente mujer, 62 años)

En sus relatos (tanto en las entrevistas como en las observaciones de las primeras consultas de los pacientes en el servicio) se trasluce el desconocimiento y el reparo en el uso de medicamentos opioides por parte de algunos profesionales, y la dificultad para escuchar y responder a sus demandas.

Para los profesionales de cuidados paliativos "acreditar como cierta esa sensación de dolor que expresa el paciente" (como señaló una médica entrevistada) constituye el punto de partida del tratamiento. En contraste con las experiencias previas de los pacientes, los profesionales de cuidados paliativos alientan la participación de los pacientes en la identificación y el reporte de las sensaciones de dolor. Como señala una paciente entrevistada:

Me siento mal, porque lo que a mí me duele no es nada en comparación a lo que ves que le duele a otros pacientes, hay pacientes que están muy mal. Vos por ahí ves a otros que andan arrastrados del dolor, pero yo no aguanto más el dolor, no quiero sufrir más dolor, mi cuerpo no acepta más dolor. [La doctora] me enseñó que mi dolor era mío, y que había que hacer algo con ese dolor mío. (Entrevista a paciente mujer, 54 años)

Este trabajo "pedagógico" -en el centro de la definición del alivio del dolor como derecho por parte de los profesionales del servicio- es una constante en las consultas clínicas. A continuación se analiza cómo los términos del protocolo de tratamiento del dolor son negociados y consensuados en la práctica, para luego discutir la formulación de una retórica del alivio del dolor y sus límites.

\section{Objetivar la experiencia subjetiva del dolor}

Para cumplir los objetivos del tratamiento es necesario evaluar la intensidad del dolor antes y 
durante el tratamiento. Uno de los predictores del mal manejo del dolor es la discrepancia entre el paciente y el médico en la estimación de la intensidad del dolor, así como los problemas para medir la intensidad (32). En el servicio, el dolor es evaluado a partir de una escala numérica, instrumento largamente utilizado para medir la intensidad del dolor en contextos clínicos, e identificado como uno de los métodos más confiables (24).

Antes o durante la consulta, los pacientes son interrogados acerca de cuán intenso es el dolor que experimentan. Para ello se les pide que adjudiquen el número que mejor represente la intensidad de su dolor, en una escala que va entre 0 (que representa la ausencia del dolor) y 10 (el máximo dolor imaginable). El número provisto por el paciente es registrado en la historia clínica, junto a otros síntomas evaluados, como cansancio, náuseas, somnolencia, etcétera. Un voluntario del servicio señala:

Voluntario: El control de síntomas tiene una escala de 0 a 10. Si es un paciente de primera vez, lo que hago es tomarle los datos y le explico que le voy a hacer unas preguntas, que se las voy a hacer cada vez que vengan a la consulta y que se le hace para hacer un control de los síntomas y evaluar cada vez que vienen cómo siguen. Entonces les empiezo a comentar que se ubiquen en una escala imaginaria de 0 a 10 y que a medida que yo le nombro los síntomas que me digan en qué puntuación están, considerando las últimas 24 horas. Y se ubican perfectamente.

Entrevistador: En estas escalas se evalúa el dolor...

Voluntario: Dolor, cansancio, náuseas, falta de apetito, somnolencia, falta de aire... (Entrevista a integrante del servicio, voluntario)

La utilización de esta escala es novedosa para la mayoría de los pacientes, y su utilización requiere de una actividad pedagógica por parte de los profesionales. Acostumbrarse a este ejercicio de objetivación les demanda tiempo a los pacientes, quienes luego reconocen las ventajas de este ejercicio: les permite hacer de su sensación algo objetivable y transmitirla a los profesionales de manera más sencilla, desafiando el carácter personal e intransmisible con el que se caracteriza a la sensación de dolor (27). Como señala un paciente entrevistado:

Entrevistador: ¿Ya lo habías hecho eso, la escala en que vos tenés que decir cuánto te duele? Paciente: Eso yo nunca lo había hecho. Al principio me costó un poquito comprender la lógica, pero me pareció fantástico, porque así uno puede transmitirle al profesional qué es, cuánto a uno le duele. Yo creo que es una objetivación subjetiva. Porque digamos intentan de alguna manera hacer posible la comunicación del dolor, y me parece interesante, porque no es que tampoco anulan otras formas de expresar lo que a uno le pasa con el dolor, porque de hecho hay un diálogo, y en ese diálogo el profesional puede ir comprendiendo si uno está mejor. (Entrevista a paciente varón, 37 años)

La escala permite a los pacientes comunicar sus sensaciones a los profesionales, quienes además de la escala utilizan otro tipo de información para definir los tratamientos y evaluar su efectividad. En muchas ocasiones, el dato que provee la escala es insuficiente, por lo que los profesionales deben apoyarse en impresiones y datos que surgen en el marco de las entrevistas con el paciente, como su bienestar general.

En algunos casos, sin embargo, se observa una mayor dificultad para traducir el dolor en términos numéricos. Interrogados sobre el "número" que le darían a su dolor, algunos pacientes responden con descripciones cualitativas ("me duele más o menos", "un poco menos que la otra vez", "mucho", "anduve mejor"), o conceden un número de la escala ante la insistencia de los profesionales ("¿entonces sería un cuatro lo que te duele?"), quienes recuerdan la importancia de obtener una medida para evaluar la eficacia del tratamiento.

Un punto de partida de los profesionales es acreditar como cierta la sensación de dolor manifestada por el paciente. Sin embargo, de acuerdo a una médica entrevistada, "esto no supone que el tratamiento sea siempre farmacológico", refiriéndose al origen "emocional" de algunos dolores. Como señaló un médico luego de una intervención con una paciente internada: 


\begin{abstract}
...es impresionante cómo los pacientes muchas veces refieren el sufrimiento a través del dolor. Asípiden dosis extra de medicación, cuando lo que necesitan es otra cosa. En este caso, pidió medicación pero necesitaba un poco de contención. (Entrevista a integrante del servicio, médico)
\end{abstract}

En estos casos se produce una discrepancia entre la intensidad reportada por el paciente y la evaluada por los profesionales. Para los profesionales es relevante identificar estos casos para ajustar el tratamiento, ensayando otras terapéuticas además de la medicación opioide. Un médico entrevistado lo explicita de esta forma:

Es bueno diagnosticar el componente emocional [del dolor] para tener en claro lo esperable en el manejo de ese dolor, y lo esperable en el rendimiento de la medicación. Está bueno también explicitarlo con el paciente, y probar con otras cosas, por ejemplo un ansiolítico. Es decir, un paciente dice que le duele 9, y conociéndolo, se podría decir que parte de ese 9 no se debe a la parte estrictamente física sino a un plus que le da la parte emocional. Y para manejar ese dolor tenés que probar con otras cosas, por ahí un antidepresivo. (Entrevista a integrante del servicio, médico)

En todos los casos, la evaluación del éxito o fracaso del tratamiento no será medido en términos binarios (la presencia o la ausencia de dolor) sino en mantener el dolor en niveles tolerables para el paciente. Para esto, la escala es un elemento central que permite observar la evolución de los pacientes a través del tiempo y ajustar el tratamiento.

\section{Negociar las imágenes sobre los opioides y el tratamiento preventivo}

El protocolo de tratamiento del dolor definido por la OMS supone incrementar la potencia analgésica de la medicación de acuerdo al aumento en la intensidad del dolor, estrategia Ilamada "escalera analgésica" (9). En primer lugar deben prescribirse analgésicos no opioides (como para- cetamol e ibuprofeno), en segundo lugar opioides débiles (como codeína y tramadol), y en tercer lugar los opioides fuertes (como metadona, morfina y oxicodona).

Las imágenes que los pacientes tienen sobre los medicamentos opioides constituyen un elemento importante en la adopción de los tratamientos y en la adherencia a estos. Las imágenes negativas sobre los opioides -en especial sobre la morfina, por su asociación con la terminalidad y por el temor a la dependencia- es uno de los principales obstáculos para el tratamiento. En palabras de un paciente entrevistado:

Yo estaba tomando Diclofenac. Yo no quería morfina, ¿viste? La morfina, juh! Pensaba que ya era enfermo terminal. Es un poco la cabeza que se hace uno. Entonces la médica me dice: "el Diclofenac te lo voy a sacar porque te va a romper los riñones, el hígado. En cambio la morfina no es nociva. O sea, cumple la misma función, la dosis es muy baja, que no te va a crear dependencia el día de mañana". (Entrevista a paciente varón, 63 años)

Como se observa en este pasaje, los profesionales buscan detectar estos temores y desarticular las imágenes negativas. Generalmente, en la primera consulta, o cuando se indica por primera vez este tipo de medicación, los profesionales trabajan sobre estos preconceptos. En estos casos, la tarea de los profesionales es contrastar esta imagen y cuestionar la asociación morfina-terminalidad ("en todas las películas al que se está muriendo le dan morfina", comenta una médica entrevistada), informando al paciente sobre las ventajas de la medicación para atender a su dolor. Un ejemplo de una primera consulta:

El médico pregunta cuál es el principal problema por el que asiste a la consulta y la paciente refiere que es el dolor en la panza, en las piernas, en la zona genital y en la cola. El médico indaga sobre el tratamiento previo, la mujer responde que fue tratado con Ibuprofeno. Entonces el médico pregunta: “¿Usted qué sabe, qué imágenes tiene sobre la morfina?". La mujer se retrae: "Ay doctor, morfina". El médico insiste: "Quiero que me 
diga lo que sabe sobre la morfina". La mujer responde: "Lo último que se le da al paciente". El profesional explica entonces que la morfina, y los analgésicos derivados de la morfina, son analgésicos fuertes, los que requieren los dolores fuertes como los que tiene la paciente. $Y$ ejemplifica: "Si yo me caigo de un balcón, y me rompo la pierna en pedacitos, voy a tener mucho dolor y me van a tener que dar morfina. Ahora, supongamos que yo me estuviera muriendo, y no tengo ningún dolor, a mí nadie me tiene que dar morfina". (Notas de campo, observación en consultas clínicas)

Estas imágenes no son privativas de los pacientes. En sus relatos sobre las experiencias de atención previas, los pacientes comentan diferentes situaciones en que los profesionales que los atendían subestimaban o trataban de forma inadecuada el dolor que manifestaban.

Otras de las imágenes negativas de los pacientes sobre la morfina es la dependencia, y el temor de los pacientes de llegar a consumir dosis altas que luego impidan controlar el dolor. En estas imágenes inciden las experiencias de familiares o allegados fallecidos por cáncer con situaciones de dolor no controlado. Por ejemplo, el hijo de un paciente comenta que su padre no sigue el tratamiento porque "le preocupa qué va a tomar cuando los dolores sean más fuertes, tiene miedo porque la vio morir a su mamá sufriendo mucho". Para algunos pacientes, el retraso en el comienzo de la medicación o las bajas dosis al inicio constituyen un reaseguro para ajustar el tratamiento cuando los dolores aumenten.

Ligado a este punto, otros de los aspectos que dificultan el tratamiento están asociados a las imágenes contrastantes entre el tratamiento preventivo del dolor y la forma de atender a estos en la experiencia cotidiana. De acuerdo al protocolo, el manejo de este tipo de dolores persistentes requiere de un tratamiento preventivo, por lo que los analgésicos se prescriben en intervalos regulares y no según la necesidad momentánea del paciente (9). Los lineamientos del tratamiento preventivo resultan contraintuitivos para algunos pacientes, que administran la medicación de acuerdo a sus necesidades diarias: es decir, toman la medicación no respetando los horarios fijados por los profesionales sino cuando sienten dolor, y dejan de tomarlo cuando no les duele. Como lo expresa una paciente entrevistada:

\begin{abstract}
Yo antes lo tomaba solamente con el dolor, entonces qué pasaba: hasta que me hacía efecto sufría unos dolores bárbaros, hasta a veces entraba en ataques, era tan fuerte el dolor que me agarraban unos ataques bárbaros. Y acá ya empecé a tomar constantemente, porque ellos me decían: cuando bajás la dosis te va agarrar el dolor y hasta que vuelvas a poner la dosis de nuevo va a pasar un ratito y vas a tener a tener un ratito de dolor. Y acá empecé a tener no-dolor. (Entrevista a paciente mujer, 47 años)
\end{abstract}

Los profesionales ponen menos énfasis en la explicación de este aspecto de los tratamientos -en comparación con el trabajo sobre las imágenes sobre los opioides-, y los ajustes suelen realizarse cuando estos problemas aparecen en las consultas.

Otro aspecto a tener en cuenta para evaluar la adherencia a los tratamientos son efectos secundarios de la medicación experimentados por algunos pacientes, como la constipación y la somnolencia, que deben ser tenidos en cuenta por los profesionales. Como lo expresa un paciente entrevistado:

Paciente: Yo no la acepté nunca a la morfina, siempre la rechacé, pero lamentablemente hay que dar gracias a la morfina que los dolores han frenado casi en un cien por cien.

Entrevistador: ¿Le generaba algún problema la morfina?

Paciente: Y... sequedad de vientre, somnolencia, falta de apetito. Eh, un poco de agresividad, porque rechazaba ese remedio. Pero la doctora me hizo entender que no es un remedio que traiga demasiadas consecuencias. (Entrevista a paciente varón, 56 años)

Si en ocasiones pueden dificultar la adherencia, cuando los dolores son muy intensos los propios pacientes pueden poner en segundo plano estos problemas, como se observa en el siguiente fragmento: 
En un momento de la consulta el paciente comenta: "Con la metadona estaba mucho mejor. El dolor es insoportable, no puedo dormir, me tiene loco". La médica le pide que diga cuánto le duele. El paciente responde: "9". La médica apunta: "Pero la morfina le producía mucha somnolencia, por eso lo rotamos a metadona". El paciente: "No me importa, prefiero dormirme pero que no me duela". (Notas de campo, observación de consultas clínicas)

\section{El alivio del dolor como derecho}

El trabajo de Scarry (31) constituye un punto de partida para pensar el dolor como un tema de derechos. En su análisis, esta autora señala que los intentos de objetivar y crear un lenguaje para el dolor (a priori definido como algo subjetivo e inefable, y que se resiste a tal objetivación) constituye un proyecto con consecuencias prácticas y éticas: "La dificultad o facilidad relativa con que cualquier fenómeno puede ser verbalmente representado incide también en la facilidad o dificultad con que ese fenómeno es políticamente representado" (31 p.12) [cursivas del original]. A partir de un abordaje centrado en el paciente, el tratamiento del dolor en cuidados paliativos se inscribe en este marco.

Se han identificado a nivel mundial diferentes iniciativas y estrategias en distintos campos (la medicina, la bioética, el derecho, entre otros) para garantizar el alivio del dolor, planteando la problemática como una cuestión de derechos humanos (5). Estas estrategias se anclan en leyes nacionales e internacionales, como las declaraciones del derecho a la salud como un derecho humano internacional (33), y en última instancia apuntan a disminuir la distancia entre la afirmación de este derecho y su puesta en práctica. En este sentido, lo que nos interesa abordar aquí no es la formulación del alivio del dolor como derecho en términos abstractos, sino la forma en que esa retórica es construida y puesta en práctica por los profesionales de cuidados en sus actividades cotidianas: es decir, cómo los profesionales encarnan estas nociones y la forma en que los pacientes se apropian (o no) de ellas.
En primer lugar debe señalarse que al momento de ser derivados al servicio de cuidados paliativos los pacientes no suelen entender el alivio del dolor como un derecho, en parte por las barreras mencionadas: ciertas ideas acerca del dolor (como inevitable, asociado a la enfermedad) o respecto a los medicamentos opioides (el temor a la dependencia, verlos como último recurso, etcétera). Esta cuestión puede observarse con claridad en los relatos de los pacientes al reconstruir sus trayectorias con el dolor, marcadas por un cambio significativo a partir de su llegada a los servicios de cuidados paliativos. Como señalaba una paciente en un extracto anteriormente citado: "[La doctora de cuidados paliativos] me enseñó que mi dolor era mío y que había que hacer algo con ese dolor", o expresiones similares que refieren al trabajo pedagógico de los profesionales del servicio, orientado a que los pacientes modifiquen sus ideas sobre el dolor y el tratamiento. Esas intervenciones apuntan a que los pacientes identifiquen el dolor, no lo minimicen ni naturalicen, y puedan comprometerse con el tratamiento. Un médico le comenta a una paciente en una consulta observada: “¿Por qué tiene que aguantar el dolor si hay algo que lo puede calmar?" O como señala una médica en la primera consulta con un paciente: "No queremos que sientas dolor, al menor dolor nos avisás". A través de la escucha atenta, alentando el compromiso de los pacientes en el tratamiento, "enseñándoles" a no desestimar sus dolores, a identificarlos, describirlos, a objetivarlos y ponerlos en discurso, los profesionales construyen y reafirman en la práctica una retórica del derecho al alivio del dolor, enmarcada en las propuestas de considerar el alivio del dolor por cáncer como una cuestión de derechos.

Esta retórica encuentra eco en algunos pacientes, que en su trayectoria en el servicio comienzan a percibir el alivio del dolor como derecho:

Como dice el doctor: "por qué vas a tener dolor si hay con qué solucionarlo". Yo creo que sí, que no podés estar con dolor si hay algo que te puede solucionar, si no lo hacen es porque no quieren. (Entrevista a paciente mujer, 57 años). 
En virtud de su experiencia -experiencia hecha cuerpo-, y de su trayectoria en el servicio, los pacientes construyen conjuntamente este derecho al alivio del dolor, que aparece como un vector para el reconocimiento de derechos en la atención médica. La experiencia de una paciente ilustra el cambio en las expectativas que se produce en algunos casos -en especial aquellos con malas experiencias previas-, y la forma crítica en que se evalúa la atención recibida previamente a partir de las nuevas realidades:

La cosa es que a las dos horas [de llegar al servicio] yo ya estaba caminando derecha, y no lo podía creer. Prácticamente derecha, a los días ya estaba totalmente derecha, era increíble. Estaba feliz, porque por primera vez en mi vida me habían sacado un dolor que tenía permanente. [...] Yo de acá [de cuidados paliativos] jamás me he ido sin saber, por lo menos sin saber qué es lo que tengo que hacer. O sin dolor me voy, o por lo menos sabiendo qué es lo que tengo que hacer para que el dolor afloje. En cambio vos ibas al oncólogo de allá, y si yo tenía algún dolor, y si estaba de buenas el oncólogo capaz que me daba algo para tomar y sacarme el dolor, y si no te ponía cara, te hacía algún gesto y vos seguías con dolor. (Entrevista a paciente mujer, 48 años)

La materialización del derecho formulado por los profesionales y apropiado por los pacientes depende de la accesibilidad y asequibilidad de los medicamentos opioides, elemento central referido en las iniciativas en torno a la cuestión $(3,5,9)$. Relevamientos previos indican que en el país existe una buena disponibilidad de preparados de opioides pero con costos elevados que limitan la accesibilidad (8). En el caso analizado, los pacientes atendidos recibían los medicamentos opioides - preparados de morfina, metadona u oxicodona- en forma gratuita en la farmacia del hospital, garantizando este derecho:

Entrevistador: ¿Y para conseguir los medicamentos, tiene alguna dificultad?

Paciente: La morfina y el opiáceo que estoy tomando ahora lo estoy pudiendo obtener a través del hospital, sin costo alguno. Y eso para mí es una ayuda importantísima, porque si yo lo tuviera que estar comprando me implicaría un costo enorme. (Entrevista a paciente varón, 37 años)

Si bien esta provisión gratuita se mantuvo a lo largo de los años en que se realizó el trabajo de campo (de 2006 a 2009), se han documentado algunas discontinuidades en la disponibilidad de alguno de estos medicamentos, obligando a la realización de ajustes por parte de profesionales y pacientes: por ejemplo, la escasez de metadona durante algunas semanas suponía que los profesionales debían variar la medicación de los pacientes -lo que se Ilama rotación de opioides-, y en algunos casos los pacientes ambulatorios tuvieron que procurar la medicación por su cuenta. Por las características mencionadas en relación con los problemas de asequibilidad de los medicamentos opioides en el país, resulta vital que la provisión gratuita sea sostenida sin interrupciones para garantizar el cumplimiento de este derecho.

Ahora bien, la retórica acerca del derecho al alivio del dolor, o la perspectiva de reducirlo a niveles tolerables, no encuentra en todos los casos un efectivo cumplimiento: algunos estudios señalan que entre el $80 \%$ y el $90 \%$ de los pacientes con dolor por cáncer pueden ser aliviados a partir de los tratamientos recomendados por la OMS (6). Esta situación genera expectativas que, en los casos en que no se logra satisfacerlas, aumentan la ansiedad y el padecimiento de los pacientes. A pesar de los avances en la terapéutica, en algunos casos no se logra controlar el dolor de los pacientes (o no a los niveles considerados tolerables por los pacientes) y la evaluación del éxito y el fracaso del tratamiento debe ser renegociada o al menos puesta en cuestión.

Considerar el dolor como un fenómeno multidimensional -es decir, que abarca cuestiones fisiológicas pero también psicológicas y emocionales-, si bien amplía el universo de significados, etiologías e implicancias, continúa siendo problemático en sus derivaciones prácticas, como lo han mostrado investigaciones previas $(13,14,19)$. Las intervenciones de los profesionales ante casos en que se sospecha una etiología emocional suelen ser menos efectivas, dado que no hay respuestas estandarizadas ni de probada efectividad, por lo que establecer la existencia de un "componente emocional" en la manifestación de dolor de los pacientes, si bien como se señaló es de utilidad 
para clarificar lo esperable en el manejo del dolor y evaluar el rendimiento de la medicación analgésica, no resuelve el problema.

Esta situación señala la dificultad de definir a priori y de manera externa los umbrales de dolor tolerable e intolerable y, en un nivel más amplio, advierte sobre los límites de la medicina para abarcar la experiencia de sufrimiento. El dolor físico, el sufrimiento, son fenómenos complejos, que suponen el cruce de aspectos culturales, sociales, fisiológicos y biográficos (16). La comunicación abierta sobre las limitaciones de la terapéutica y de los dolores difíciles de tratar permite ajustar las expectativas de los pacientes, que deberían ser informados de las perspectivas de las intervenciones.

\section{CONCLUSIONES}

En este artículo se analizaron las estrategias de los profesionales de cuidados paliativos para instrumentar y consensuar los términos del protocolo de tratamiento del dolor por cáncer, así como las intervenciones para mejorar la adherencia. La asociación de la morfina con la terminalidad, el temor a la dependencia, los efectos secundarios de la medicación y las contradicciones entre el tratamiento preventivo y la forma de atender al dolor en la vida cotidiana funcionan como obstáculos para la adopción y la adherencia al tratamiento, sobre los que los profesionales trabajan activamente. El tratamiento se inscribe en la propuesta de considerar el alivio del dolor como una cuestión de derechos, retórica que los profesionales construyen y afirman -en colaboración con los pacientes- en la práctica cotidiana.

Pese a los avances de la medicina en esta área, el tratamiento del dolor continúa siendo un aspecto problemático en los servicios de salud, que deberían garantizar el derecho de este tipo de pacientes a acceder a una atención adecuada y competente y a la medicación necesaria. El artículo discute una temática poco abordada en el país, a la vez que contribuye a generar interrogantes relevantes para la investigación y la intervención en salud pública, como por ejemplo el tratamiento del dolor por cáncer, los conocimientos de los profesionales sobre el uso de medicamentos opioides y la disponibilidad y condiciones de accesibilidad a este tipo de medicamentos.

\section{NOTAS FINALES}

a. En 2006 el consumo promedio de morfina y metadona en Argentina era de 0,66 mg y 0,24 mg per cápita, mientras la media global era de 8,74 mg y 5,98 mg (8).

b. Se reserva el nombre de la institución para proteger el anonimato de las personas involucradas.

c. Las entrevistas se realizaron en el marco de un proyecto UBACYT dirigido por Mario Pecheny que analiza las imágenes y prácticas en torno a la autonomía en el campo de la salud en diferentes grupos de pacientes, y una investigación dirigida por Hernán Manzelli sobre la noción de satisfacción en cuidados paliativos en el marco de una beca del Ministerio de Salud de la Nación.

d. Stake (29) diferencia los estudios de casos intrínsecos, en el que la selección del caso es guiada por un interés en comprender el caso particular, y estudios de caso instrumentales, en que el caso es examinado para profundizar en un tema o refinar una teoría. Esta investigación se ajusta a este último tipo: el servicio cuenta con un equipo interdisciplinario especializado en este tipo de abordaje, y atiende a pacientes en distintos niveles de evolución de la enfermedad.

\section{AGRADECIMIENTOS}

La investigación se financió con una beca doctoral del Consejo Nacional de Investigaciones Científicas y Técnicas (2006-2011) y con una beca de iniciación a la investigación sanitaria de la Comisión Salud Investiga del Ministerio de Salud de la Nación (2008-2009). Sin la predisposición y buena voluntad de los profesionales del servicio, y en especial de los pacientes y sus familiares, la investigación no hubiera sido posible. Agradezco los comentarios y sugerencias de los evaluadores anónimos que me han permitido enriquecer el artículo. 


\section{REFERENCIAS BIBLIOGRÁFICAS}

1. Baszanger I. Douleur et médecine, la fin d'un oubli. Paris: Éditions du Seuil; 1995.

2. Swederlow M, Stjernsward J. Cancer pain relief: an urgent problem. World Health Forum. 1982;3(3):325-330.

3. Cohen J, Ezer T, McAdams P, Miloff M, editores. Los cuidados paliativos y los Derechos Humanos: Una guía de recursos. México: Open Society Institute, Equitas; 2007.

4. Brennan F. Palliative care as an international Human Right. Journal of Pain and Symptom Management. 2007;33(5):494-499.

5. Brennan F, Carr D, Cousins M. Pain management: a fundamental Human Right. Anesthesia \& Analgesia. 2007;105(1):205-221.

6. O'Mahony S. Cancer pain: prevalence and undertreament. En: Bruera E, Portenoy R, editores. Cancer pain: assesment and management. Cambridge: Cambridge University Press; 2003. p. 38-47.

7. Hearn J, Higginson IJ. Cancer pain epidemiology: a systematic review. En: Bruera E, Portenoy $\mathrm{R}$, editors. Cancer pain: assesment and management. Cambridge: Cambridge University Press; 2003. p. 19-37.

8. Wenk R. Cancer pain-progress and ongoing issues in Argentina. Pain Research \& Management. 2009;14(5):350-351.

9. World Health Organization. National cancer control programmes: policies and managerial guidelines. Ginebra: WHO; 2002.

10. Seymour J, Clark D, Winslow M. Pain and paIliative care: the emergence of new specialities. Journal of Pain and Sympotom Management. 2005;29(1):2-13

11. Zborowski M. Cultural component in reponse to pain. Journal of Social Issues. 1952;8(4):16-31.

12. Baszanger I. Pain: Its experience and treatments. Social Science \& Medicine. 1989;23(3):425-434.

13. Csordas T, Clark J. Ends of the line: Diversity among chronic pain centers. Social Science \& Medicine. 1992;34(4):383-393.

14. Jackson J. "After a while no one believes you": real and unreal pain. En: Delvecchio-Good MJ, Brodwin PE, Good BJ, Kleinman A, editors.
Pain as human experience: An anthropological perspective. Los Angeles: University of California Press; 1994. p. 138-168.

15. Bendellow G, Williams S. The end of the road?: Lay views on a pain-relief clinic. Social Science \& Medicine. 1996;43(7):1127-1136.

16. Good B. Medicine, rationality, and experience: An anthropological perspective. Cambridge: Cambridge University Press; 1994.

17. Delvecchio-Good MJ, Brodwin PE, Good BJ, Kleinman A, editors. Pain as human experience: An anthropological perspective. Los Angeles: University of California Press; 1994.

18. Aldrich S, Eccleston C. Making sense of everyday pain. Social Science \& Medicine. 2000;50(11):1631-1641.

19. Del Mónaco R. Dolor crónico, corporalidad y clausura: percepciones y experiencias sobre la migraña. Revista Latinoamericana de Estudios sobre Cuerpos, Emociones y Sociedad. 2012;4(8):17-28.

20. Winslow M, Clark D, Seymour J, Noble B, ten Have $\mathrm{H}$, Meldrum M, Paz S. Changing technologies of cancer pain relief: themes from the twentieth century. Progress in Palliative Care. 2003;11(5):256-260.

21. Clark D. "Total pain", disciplinary power and the body in the work of Cicely Saunders, 1958-1967. Social Science \& Medicine. 1999;49(6):727-736.

22. Kleinman A. The illness narratives: Suffering, healing and the human condition. New York: Basic Books; 1988.

23. Le Breton D. Antropología del dolor. Barcelona: Seix Barral; 1999.

24. Noble B, Clark D, Meldrum M, ten Have $H$, Seymour J, Winslow M, Paz S. The measurement of pain, 1945-2000. Journal of Pain and Symptom Management. 2005;29(1):14-21.

25. Meldrum M. The ladder and the clock: cancer pain and public policy at the end of the twentieth century. Journal of Pain and Symptom Management. 2005;29(1):41-54.

26. Pope C, Mays N, editors. Qualitative research in health care. Oxford: Blackwell; 2006.

27. Guber R. La etnografía: Método, campo y reflexividad. Buenos Aires: Norma; 2001. 
28. Strauss A, Corbin J. Basics of qualitative research: techniques for procedures for developing grounded theory. London: Sage; 1998.

29. Stake R. Case Studies. En: Denzin N, Lincoln Y, editors. Handbook of Qualitative Research. California: Sage; 1994.

30. Manzelli $H$, Bertolino $M$, Gutiérrez Taddío M, Pecheny M, Farías G, Cullen C. Satisfacción en cuidados paliativos: un abordaje cualitativo. Buenos Aires: CEDES; 2004.

31. Scarry E. The body in pain: the making and unmaking of the world. New York: Oxford University Press; 1985.
32. Anderson $\mathrm{K}$, Cleeland $\mathrm{C}$. The assessment of cancer pain. En: Bruera E, Portenoy $R$, editors. Cancer pain: assesment and management. Cambridge: Cambridge University Press; 2003.

33. Comité de Derechos Económicos, Sociales y Culturales. Observación general No 14: El derecho al disfrute del más alto nivel posible de salud (Artículo 12 del Pacto Internacional de Derechos Económicos, Sociales y Culturales) [Internet]. Ginebra: Naciones Unidas; 2000 [citado 10 may 2012]. Disponible en: http://daccess-dds-ny.un.org/doc/ UNDOC/GEN/G00/439/37/PDF/G0043937. pdf?OpenElement.

\section{FORMA DE CITAR}

Alonso JP. El tratamiento del dolor por cáncer en el final de la vida: estudio de caso en un servicio de cuidados paliativos de la Ciudad Autónoma de Buenos Aires. Salud Colectiva. 2013;9(1):41-52.

Recibido el 30 de mayo de 2012

Versión final presentada el 5 de octubre de 2012

Aprobado 20 de diciembre de 2012 